Northern Review

yukoncollege.yk.ca/review

\title{
Mobile Miners: Work, Home, and Hazards in the Yukon's Mining Industry
}

\section{Christopher Jones and Chris Southcott}

\begin{abstract}
The Yukon is on the verge of a resource boom. A major change since the early 1980s has been mining companies' increasing reliance on long-distance commuting to move their workers to mine sites. While long-distance commuting can be seen as reducing the benefits the Yukon receives from mining, it can also be seen as an effective way of reducing the negative impacts that arise from the boom and bust nature of the industry. Long-distance commuting also represents new opportunities for workers currently living in the Yukon. It represents the potential for longer-term employment without the need to continually move to different communities. Yet little has been written about the attitudes of these workers towards their employment situation. What are their major concerns? Are there specific concerns relating to their mobile lifestyle? As an exploratory attempt to answer these questions, this articley examines twelve in-depth interviews with respondents from diverse backgrounds who worked in the Yukon's mining industry. The findings indicate that workers in long-distance commuting mining firms had a range of perspectives regarding their workplaces. Some are general concerns that are not unique to their mobile lifestyle, while others relate directly to this. In terms of long-distance commuting, it appears most workers responded positively and were content to travel. While the sample size was small, the research suggests several avenues for further research such as the situation of women in new mining operations, Aboriginal employment experiences, perceptions of safety, and the separation of home and work.
\end{abstract}

\section{Introduction}

In 2012, the Yukon, as it has been numerous times in the past, was on the verge of a resource boom. Three mines were in operation and four others were at various stages in the development process. At the time, the Yukon's mining industry employed about 600 workers and was seen to have the 
potential to employ another 1,000 (Paslowski, 2012). While the years since have seen a downturn, the boom period allowed us to see that the Yukon's mining industry - and the Canadian mining industry in general-has been in a period of transition since the 1980s as it changes from an industry based on Taylorist work practices and Fordist regulation, to an industry based on flexible and lean production practices.

A major change since the early 1980s has been mining companies' increasing reliance on long-distance commuting to move their workers to mine sites (Storey, 2010b). While long-distance commuting can be seen as reducing the benefits the Yukon receives from mining, it can also be seen as an effective way of reducing the negative impacts that arise from the boom and bust nature of the industry. Long-distance commuting also represents new opportunities for local workers currently living in the Yukon. ${ }^{1}$ It represents the potential for longer-term employment without the need to move outside the region. ${ }^{2}$ In order for the Yukon to maximize the benefits of this new employment arrangement, a better understanding is needed of the issues that these workers are currently facing.

This article is a first step in this regard. Changes to mining firms in the Yukon have affected workers in a variety of ways, and this article explores those ways by analyzing twelve in-depth interviews with respondents who worked in Yukon's mining industry. The primary objectives were to identify the major concerns of workers, and find out if these concerns were related to their mobile work experience. These respondents came from diverse backgrounds, and their experiences-as men and women, local and non-local workers, Aboriginal and non-Aboriginal people, labourers, tradespeople, and professionals - help us understand the impacts these new work processes have for workers.

Given the limited sample size, it is difficult to make generalizations about the findings. As an exploratory study, our primary purpose was to develop a series of potential tendencies that could be researched in more detail. As such, our findings indicate that workers in long-distance commuting mining firms had a range of perspectives regarding their workplaces. Many are sentiments that are most likely shared with non-mobile workers in the mining industry. Most workers described a close-knit, masculine, workplace culture at their mines. However, two groups of underrepresented minorities in mining, women and Aboriginal people, may face issues in entering and staying in this industry. Women were described by respondents as welcome, yet were also described as being concentrated in low-paying support roles and absent from underground mining positions. General comments also indicate that Aboriginal people may face negative workplace environments 
at these mines. Additionally, some respondents brought up issues with safety in their workplaces. These issues could all be barriers to hiring and retaining a diverse local workforce at long-distance commuting operations.

In terms of long-distance commuting itself, most workers interviewed responded positively and were content to travel; they felt long-distance commuting was part of the mining lifestyle. However, local and non-local workers travelled for different reasons. Local workers appeared to be concentrated in labourer positions and their jobs were described as precarious, forcing them to travel often to new, often temporary, jobs. The two non-local workers interviewed, both tradespeople, noted many opportunities to work outside of their regions and the mining sector, and travelled to take advantage of these high-paying positions. In terms of home life, those local, unmarried workers who were interviewed seemed to enjoy the lifestyle and were willing to travel long distances for work. Those interviewees who were nonlocal workers with families provided more mixed experiences. It appeared that those who were highly experienced in long-distance commuting may have adjusted to this lifestyle, while novices travelling long distances could experience more fatigue in both their commute and home lives.

\section{The Changing Face of Mining}

For most of the twentieth century, Canada's mining industry tried as much as possible to rationalize production through the use of accepted industrial organization. This has impacted the experience of those working in the mining industry. In the early twentieth century, Frederick Taylor wrote a treatise on workplace organization entitled The Principles of Scientific Management where he argued that workplaces could be made more efficient by having workers and managers work together to identify the best ways to complete tasks. Managers organized and planned work tasks to be as efficient as possible while workers completed the specific tasks laid out for them. By dividing the labour process in this way both employers and employees benefited; employers would enjoy higher productivity and therefore higher profits, which they would pass on to employees as higher wages (Taylor, 1911, p. 10-12). In discussions of resource development, this system has been linked to Fordism (Hayter, 2003; Jenson, 1989).

By the early 1980s Canada's mining industry began to change. A global recession caused a decline in mineral prices, and the mining industry began a period of restructuring (Storey, 2010b, p. 28). Lean production originated in Japan with auto manufacturers in the early 1980s as a new way of organizing the workplace. In contrast to Taylorism's strict division of workers' labour into specific tasks or jobs for efficiency, lean production 
emphasized efficiency and flexibility in the workplace (Roos, Womack, \& Jones, 1991). Companies now had to make due with a smaller workforce at a time of rapid technological change and increased global competition. This new, lean, workforce had to learn a variety of new skills and take part in decision making. This would supposedly lead to greater job satisfaction in the workplace (Russell, 1999, pp. 15-23). But lean production was also potentially dangerous, because workers may also be exploited by employers more easily. For example, greater decision making and flexibility in jobs performed could place greater responsibility and workload on workers for no increase in pay (Russell, 1999, pp. 1-3).

Canada's mining industry changed in two other ways at this time, specifically in terms of new technology and the development of new mines. The development of new technology allowed automation and mechanization of some work processes in mining. Consequently, demand for general labourers decreased and many were laid off in mining, but at the same time demand for skilled workers to operate these new machines increased (Russell, 1999, pp. 120-128; Storey, 2010b, pp. 25-26). In terms of development, new mines were built farther away from urban centres, and with shorter projected lifespans. Companies and governments were unwilling to support expensive mining towns, only to have them shut down when mines closed in a few years (Storey, 2010b, p. 28). Companies found a solution by building camps at the sites of mines. These camps were small relative to the old mining towns, and provided basic accommodations for workers while they lived and worked at the mine site (Storey, 2010b, p. 29). Companies now expected workers to travel to these camps from home for long shift rotations. Today these rotations vary depending on each project, but are usually between two and four weeks at work and home (Costa, Silva, \& Hui, 2006; Storey, 2001). These new working conditions are often known as fly-in fly-out, or FIFO, operations, but can also take other forms such as drive-in drive-out, or DIDO.

These new operations help companies and governments avoid many of the costs and political problems associated with building a town. They result in a leaner and more flexible operation that requires less physical infrastructure than the building of a new community. FIFO may also be beneficial to the regions where the operations are taking place. The boom and bust cycle associated with mining has led to many problems that FIFO has the potential to avoid. While FIFO workers mean the loss of potential wages that are spent locally, the benefits of avoiding at least some of the negative impacts of boom periods and some of the costs of bust periods may result in more sustainable economic growth. In addition, local workers from the 
region can themselves learn to take part in FIFO operations. Local workers in resource regions can themselves use the FIFO experience in their regions to become FIFO workers both within their region and in operations outside their regions. As such, their wages would continue to provide benefits to these regions.

The potential for employing FIFO operations in a manner that maximizes benefits to northern communities and minimizes negative impacts depends on an appropriate balance of FIFO workers and local workers (see Carrington \& Pereira, 2011). This balance can be disrupted by an inability to understand the conditions facing FIFO workers-both from outside the region and within the region. An inability to understand the perception of outside workers may lead to operations having problems attracting these workers. This may have a negative effect on the efficiency of these operations. If the region benefits economically from these operations in the form of royalties and other benefits, then such a situation would have a negative impact on the region. As well, if the region hopes to integrate workers from the region into FIFO operations, a better understanding of the particular conditions of these workers is essential.

\section{The Yukon and the New Mining Industry}

The Yukon serves as an excellent case study for examining changes in the Canadian mining industry and its impact on workers. The territory is heavily dependent on natural resources, and may be on the verge of a mining boom (Paslowski, 2012). In past boom periods, many of the benefits from resource extraction have flowed south-southern workers and companies came and worked and left, or the federal government has controlled the conditions of resource extraction for the territory (Coates \& Morrison, 2005, pp. 293-299). Today the situation is different; the Yukon now controls its natural resources and regulations as many of these responsibilities were transferred from the federal to the territorial government with devolution. Additionally, First Nations are now self-governing in the territory, and sign Impact Benefit Agreements (IBAs) with mining companies (Coates \& Morrison, 2005, pp. 300-316; Horne, 2010). The goals of these agreements are generally to ensure First Nations communities benefit from developments on their lands (Gibson \& Klinck, 2005; O'Faircheallaigh, 2010).

There are still challenges in the Yukon's mining industry despite the above changes. If mining returns in force to the Yukon it will likely be organized around the lean production work processes described above; this means a highly skilled, highly mobile workforce will be necessary to work in the industry. Indeed, a study conducted by the Mining Human 
Resources Council (MiHRC) (2011b) forecasts that knowledge workers will become increasingly important in the Canadian mining industry over the next decade. There are concerns that the local workforce cannot do the skilled jobs that will be available. A survey of the Yukon businesses indicates that one of the greatest problems employers have is recruiting local workers with adequate education or training to perform their jobs (Yukon Bureau of Statistics, 2010).

If this is true, mining companies may fly in outside workers to fill these skilled positions, as they have done in other regions and countries. This would result in a fly-over effect, where the benefits of employment are lost despite mines being developed and operated locally (Ritter, 2001; Storey, 2001). Additionally, there have been concerns in the Canadian mining industry that not enough is being done to recruit women and Aboriginal people (Costa et al., 2006; Gibson \& Klinck, 2005; MiHRC, 2011a). If the Yukon is to benefit from this boom, its local workers - including both women and Aboriginal people-must be able to fully participate. This article updates previous work in the Canadian mining industry and examines the process of longdistance commuting in a new context. It builds on the work of Russell (1999) in examining the Canadian mining industry. It examines whether there is a need to update Russell's work by including the experiences of Aboriginal people, women, different occupations, local and non-locals, as they work in a lean Yukon mining industry that uses long-distance commuting to get its workers from home to remote mine sites. This is particularly relevant today as labour migration has become more prevalent in recent years (Newhook, Neis, Jackson, Roseman, Romanow, \& Vincent, 2011). Similar studies have been conducted, which examine workers employed in long-distance commuting operations, but many of these studies were completed in the 1980s or in different contexts. For example, past studies have examined long-distance commuting in Australia's mining industry (Storey, 2001, 2010a; Torkington, Larkins, \& Gupta, 2011), or in the United Kingdom's and Canada's oil industries (Collinson, 1998; Lewis, Porter, \& Shrimpton, 1988a). Therefore, this study not only updates older work in Canada's mining industry and elsewhere, it does so in an area never explored before: the Yukon's mining industry.

This article asks the following question: What were the main employmentrelated concerns of FIFO workers in the Yukon? To answer this question, twelve in-depth interviews were conducted in February 2013 with workers involved in the Yukon's mining industry. ${ }^{3}$ Purposive sampling from local mining organizations was used to recruit the initial three respondents. ${ }^{4}$ From these key respondents, snowball sampling was then used to recruit 
the remaining nine respondents. These workers came from a range of backgrounds in terms of gender, age, ethnicity, and place of residence. In addition, they represented different occupational groups, including labourers, tradespeople, and professionals. At the time the interviews were conducted, only the two participants from outside the Yukon were engaged in fly-in fly-out commuting while the others were engaged in drive-in driveout commuting that took at least two hours. Many of those currently driving had engaged in FIFO previously. The interviews were semi-structured and revolved around a series of questions relating to concerns with the general work environment followed by concerns relating to commuting.

The twelve in-depth interviews, all conducted in Whitehorse, were transcribed and analyzed using NVivo qualitative data analysis software. The majority of respondents were local Yukon residents, males, labourers, and white. At least two respondents represented professionals, tradespeople, non-local residents, and Aboriginal people. Only one respondent was female. The respondents' main characteristics are summarized in Table 1.Their experiences provide an initial understanding of how workers in the mining industry can have different experiences depending on their different backgrounds.

Table 1. Respondent profiles

\begin{tabular}{ccccccc}
\hline Number & Name & Sex & Race & $\begin{array}{c}\text { Marital } \\
\text { Status }\end{array}$ & Occupation & Residence \\
\hline 001 & Adam & M & Aboriginal & Divorced & Labourer & Yukon \\
002 & Barry & M & White & Married & Professional & Yukon \\
003 & Charlie & M & White & Common-law & Trades & Quebec \\
004 & David & M & White & Married & Professional & Yukon \\
005 & Elvis & M & Aboriginal & Divored & Labourer & Yukon \\
006 & Frank & M & White & Common-law & Labourer & Yukon \\
007 & Grace & $\mathrm{F}$ & White & Single & Labourer & Yukon \\
008 & Hugh & $\mathrm{M}$ & White & Divorced & Labourer & Yukon \\
009 & Irving & $\mathrm{M}$ & White & Common-law & Labourer & Yukon \\
010 & Jeremy & $\mathrm{M}$ & White & Single & Trades & Yukon \\
011 & Kirk & $\mathrm{M}$ & White & Single & Labourer & Yukon \\
012 & Leo & $\mathrm{M}$ & White & Married & Trades & BC \\
\hline
\end{tabular}


While respondents discussed a number of concerns linked to longdistance commuting work in the mining industry, most can be organized around four major themes: workplace culture, safety in mining, mobility and migration, and home life. The themes of workplace culture and safety in mining are not specific to workers engaged in long-distance commuting, but are discussed here because they were seen as important to the respondents and influence their general feelings toward participating in a commuting lifestyle linked to mining.

\section{Workplace Culture}

Respondents spoke most frequently, and in greatest detail, about the workplace culture at long-distance commuting operations. This theme can be divided further into the size and type of mine worked at, the masculine work environment at the mine site, and the environment for both Aboriginal people and women in mining. Two structures of mines affected respondents' experiences and the kind of culture that emerged in the workplace. First, the size of mines mattered. Respondents noted that large mines employed greater numbers of workers, with entire departments devoted to different functions. This resulted in a higher division of labour. By contrast, small mines often lacked specialized departments. Therefore, because of a lower division of labour at these mines, workers were more likely to fill a variety of roles and perform many tasks. Neither size was necessarily described as better or worse, although Charlie, a tradesman, enjoyed the range of experience he gained from performing different tasks in a small mine.

Second, according to the respondents, the type of the mine also affected workers. Open-pit mining was perceived to be monotonous work, and consisted mainly of driving trucks of dirt and ore between two points for the duration of workers' shifts. Underground mining was perceived as more dangerous; the environment was wet and dirty, and full of falling rock hazards and potential cave-ins. This close, dangerous environment was described by respondents as one that created solidarity between workers. Several respondents insisted that they had to be able to trust fellow crew members with their lives. Respondents spent weeks at a time-both on shift and off-with their crews, and deep personal friendships were often described. In one respondent's words, "Soon you're spending half your life with them. They're like a second family" (Interview, Adam).

It was the small underground mining operations described above that were often the focus of respondents. As underground mining is almost exclusively a male domain, a strong masculine workplace culture became apparent throughout the interview process. Respondents discussed many 
of the attributes they believed were necessary to succeed in this kind of mining. To succeed, workers needed to enjoy the work they did at the mine. Respondents also said workers needed to be physically and emotionally tough. Many respondents brought up this concept of toughness, a willingness to endure pain, get dirty during the job, and work in exhausting conditions. Some respondents brought up workers they believed didn't belong in mines, termed "whiners" by Elvis, a labourer. These workers complained about the conditions of mines, and according to Elvis would quit after a few weeks of work. Another labourer, Adam, may have been the kind of worker that Elvis called a "whiner." Adam raised concerns at safety meetings and recalled being scolded for complaining about missing equipment. He felt that if workers raised too many issues, they risked losing their jobs. Some typical beliefs and attitudes of workers are described below:

Oh I loved the physical work. I loved it. I looked forward to it, every day. I even did things the long way [laughing]. No you, you have to get to love it, otherwise you might as well forget it, eh? (Interview, Elvis)

There's a big rivalry there, eh? We're not allowed to play hockey in the camp anymore because we used to play against the mill guys and the miners. And the mill guys were always getting hurt so ... lost time accidents. The old saying, 'rough and tough miners need only apply.' Yeah. Other than that, it was pretty good. (Interview, Frank)

I'm a very strong worker. I'm a workaholic. And I like, I've been doing a lot of, how you say, manly work, like physical work. (Interview, Grace)

Other respondents brought up the competitive nature of mining, citing hockey games between mill and mine workers. Competition also entered the workplace between shifts and some respondents brought up regionalism as an issue. For example, workers from one area of Canada competed with workers from another area of the country. Last, aggression came up as a problem in mining. Charlie, a tradesman, described some workers going "haywire" in the mine. This referred to some workers verbally abusing others over workplace conflicts, or taking unsafe actions in moments of anger. Charlie cited examples of workers driving machines dangerously, or screaming at other workers over minor issues.

Given the history of Aboriginal peoples in the Yukon, the presence of First Nations communities and governments throughout the Yukon, and 
their past exclusion from mining jobs, respondents were asked about the inclusion of Aboriginal people in their workplaces. Two professionals, Barry and David, acknowledged that underground mining is still dominated by white men, although most respondents said more women and Aboriginal people were entering the mining industry. When asked about hiring practices, several respondents said "a good number" of Aboriginal people were hired at their mines. There were also opportunities for advancement; Leo, a tradesman, knew an Aboriginal man who began as a helper (a kind of general labourer) and worked his way into a paid apprenticeship program for a trade at the mine. In general, though, the majority of jobs available to Aboriginal people are at the bottom of the occupational hierarchy. Most respondents noted that Aboriginal people were employed as general labourers, equipment operators, or cleaning and catering staff.

In addition, respondents brought up the issue of Aboriginal people losing their jobs, either voluntarily or involuntarily, with different reasons described. According to two labourers, Jeremy and Kirk, Aboriginal people easily found employment through their First Nation in entry-level positions, but would leave after short periods of time, such as a week. They were asked why this happened. According to both Jeremy and Kirk, the issues were wide-ranging; some found the work too hard and quit; some were sent home for not doing their jobs; and others were fired for alcohol or drug use. To Kirk, the main issue was that mining companies were forced to keep a certain proportion of Aboriginal workers, even if they could not find qualified ones. Jeremy largely agreed with Kirk, and added that some Aboriginal people felt they were guaranteed a job. By contrast, Adam, an Aboriginal labourer, felt that racism was a major problem at the mines he worked. He agreed with Jeremy and Kirk that Aboriginal people were able to get hired, but added that keeping their jobs once hired was a larger problem. He said the Aboriginal people were treated differently at the sites he worked, and cited specific examples. He recalled being passed over for promotion or training, despite having seniority over workers who got those promotions. When rules surrounding alcohol or marijuana use were broken (a regular occurrence at some sites according to Adam and another respondent, Grace), Aboriginal people were treated more harshly than other workers, often losing their jobs instead of being written up. To Adam, part of the problem was the attitude expressed by Jeremy and Kirk, which created a negative environment for Aboriginal people. 
Interviewer: Do you think racism is a big problem in the mining industry?

Respondent: Yes, it is. People think we got a job just because we're natives. 'Cause they're workin' our First Nation's lands. A lot of them feel that the only reason you're out here is 'cause you got a land claims settlement, it's the only reason you got a job. So they make it hard for you, a lot of times you don't want to go back. Or you're not a happy camper. So, a lot of times people won't go back because they're being abused. So it's like, 'oh you guys don't wanna work.' No, we don't wanna be abused. And there's nobody there to defend us. Nobody in our central government. Nobody in the Yukon government, our First Nations government. They just think 'oh we're gonna get jobs.' Well once we get the jobs, we gotta fight to keep 'em. And it's a big struggle to get respected and appreciated, no matter how hard you work. (Interview, Adam)

In addition to discussing equity issues regarding Aboriginal people, respondents discussed women in the Yukon's mining industry. The majority of respondents said hiring practices were positive, and that the gender gap in the mining industry was closing. David, a professional, said that women were well accepted in open-pit mining. Most respondents noted that women were largely entering the mining industry in the support services. Many worked in catering or housekeeping, while others worked as administrative assistants in offices at the mines. In terms of underground mining, most respondents noted that women were absent in underground mining.

I would say that, that the construction and the drilling and that stuff is really, still extremely dominated by the, the, by males. I've never even seen a diamond driller, or a diamond driller helper that is female. (Interview, Barry)

In fact, Barry, a professional, had never seen a female driller underground. No respondent gave a ready explanation for why women were absent underground, although David noted an old mining superstition that women underground was considered a bad omen and told an amusing story where he was almost fired for bringing a woman underground. Grace, a labourer and the sole female respondent, reported that she felt welcome in her workplace, and framed any problems in the workplace as issues with management or individual workers, rather than in terms of gender. 
Safety in Mining

Second only to workplace culture, respondents spent significant time talking about safety in their workplaces. As noted above, this is not an issue specific to long-distance commuting, but is discussed here because respondents felt it was important to their situation as commuting mine workers. Most respondents emphasized that they felt safe in their workplaces, but some issues were also raised. As discussed above, mining, and in particular underground mining, can be dangerous work. Some respondents said that the work was inherently dangerous because of the type of ground they worked. Underground mining was seen by workers as the more dangerous form of mining, not only due to cave-ins and blasting, but also because of the ground with which one worked. "Bad ground" was a term that came up regularly and meant that the ground was difficult to drill into, would slow down progress, and in terms of safety could result in cave-ins or cause injuries. The Minto and Bellekeno mines in the Yukon were repeatedly named by respondents for having bad ground, especially when compared to other mines they had worked, for example in the Northwest Territories.

Interviewer: What didn't you like about [Yukon mine]?

Respondent: Oh I just didn't like the ground. It's too dangerous. And you can go to work over in Yellowknife and somewhere like that the ground is fuckin' solid. No timber nowhere. [Yukon mine] is just covered in timber. Every time you break a piece of ground you gotta put up timber. (Interview, Elvis)

Issues surrounding availability of training and equipment at mine sites were also raised by respondents. Last, respondents spent time discussing safety meetings and the various practices in their workplaces that made them safe.

Despite this, the vast majority of respondents brought up how safe they felt in their workplaces. The reasons for these feelings were the availability of equipment, proper training on equipment, safety meetings, and company practices. Still, some respondents raised some concerns about safety in the workplace. Grace, a labourer, brought up that her work in the mill required her to handle chemicals to separate the metal from other rocks. Her equipment included safety glasses, gloves, and overalls. She noted that as a small woman, equipment was often not available in her size and would snag and rip on machinery or corners. She noted that cost and distance was a factor here for the company; they would order in the equipment she needed but this took time and they worked in remote locations. In the meantime, she would have to use defective equipment. Charlie, a tradesman, brought 
up equipment needed for his department; he wrote up a list of tools needed for workshop, but his company was only willing to pay for about ten percent of it. This would cover the cost of one good power tool, leaving him with inadequate equipment to do his job properly. One respondent brought up many unsafe practices at a particular mine, and the high turnover that these practices created:

[Experienced miner], he's a big gun. He can drill. He's a good driller, he's a good driller underground. I mean, he can do 'er. He can get shit done. So when this guy has been drillin' all his fucking life... and he walks into a mine for uh, three days ... and says, 'Fuck this guys. I'm outta here. You're all gonna get killed.' And me and fucking [partner] continue to work after our driller is gone. (Interview, Hugh)

\section{Mobility and Migration}

A key feature of the mining workforce, even prior to contemporary times, has been its transient nature. Respondents talked about their mobile lives, and their experiences varied depending on a number of factors, including occupation, age, and residence. Commuting long distances to mine sites in the Yukon was not seen as a problem by workers who were young, local, and single. For older respondents, mobility was described as a "way of life," and these workers also discussed the changes in migration in the Canadian mining industry from the early 1970s to the present. The two tradespeople interviewed, both non-local and married workers, talked about the challenges that their mobile lifestyle created, but also the opportunities that it brought.

Miners are known to just up and quit at the drop of a hat ... it's the top, number one industry where people just quit numerous times in a year [laughs]. To go with another contractor, or go back with another contractor they were with three years previous. It's hilarious. They bounce around. (Interview, Charlie)

Yeah I kinda float around. (Interview, Adam)

Long shifts and travel have been important features of the Canadian mining industry for decades, as older respondents noted. Respondents David, Elvis, and Frank reflected on their time in the 1970s, when they first began working in mining. David worked as a professional in the Far North for several years, where a camp had to be constructed around a mine. Workers had to stay for six months at a time at this site. Respondents Elvis and Frank both worked as labourers in the Yukon or Northwest Territories 
mines during the 1970s, and recalled working for six weeks at a time. By the 1980s this arrangement began to change, with companies requiring two- or three-week rotations in and out of camp.

For the local workers interviewed, long-distance commuting was not seen as an issue, and was seen as enjoyable. For young and single respondents, the commute was described as a pleasant experience. Local labourers Grace, Jeremy, and Kirk all drove about two to five hours to get to mines in the Yukon, and described the drive positively as relaxing or exciting. When they left the mine, the drive back was described as a celebration. In addition, local workers liked having vehicles at the mine so they could leave after shift to go fishing, hunting, or into town.

Releasing. It's easy. It's fun. I'm sitting in the truck and I'm listening to my music and I'm smoking my cigarette and [laughing] planning, 'oh what am I gonna do my first day? Oh drink beer? And the second thing I'm gonna do? [laughing] Oh eat a good meal.' And that's the two things, I'm sure that's the two things coming out of the head of anybody coming out of the camp. (Interview, Grace)

Awesome, just blare music and drink beer, except for the driver of course-the driver stays sober til we get there [laughing]. And then we have a bit of an evening party and then all go back to our ways, and meet together ... two days from now. (Interview, Jeremy)

This could be contrasted with the two non-local respondents who had mixed feelings about commuting long distances to Yukon mines. Often their commute was two days long, with multiple flights and a stay in Whitehorse before continuing to the mine. Charlie noted that this lost time, combined with shift work split between days and nights, led to exhaustion on the job and when returning home. Leo did not appear to have this issue, despite both Charlie and Leo having families. The main difference was that Charlie was relatively new to long-distance commuting in mining, while Leo had established a family and been commuting for about twenty-five years.

Yeah it can be a little overwhelming. I, I always take the [flight] back east from Vancouver to [eastern Canada], so I arrive at seven in the morning. By the time I usually get my bags and on the road I'm usually home just before lunchtime ... It takes time to adjust. Plus, the rotation that we do up at [Yukon mine] right now was, we come in and we do two weeks of day shift, and then halfway through that four week run we switch to nights for the last two 
weeks. So, y'know, not only am I overwhelmed when I get home, I am sleep deprived. So it takes definitely a few days to adjust. (Interview, Charlie)

I've worked at places where you've worked a week in and a week out, and it's a four or five hour drive each way, and ... I've worked, when I worked overseas it took you two days to get there and two days to get home. So, I guess the travel part of it I'm kind of used to. (Interview, Leo)

Occupation also played a role in mobility. For general labourers and helpers, mainly local workers, older workers talked about mobility as a way of life in the "old days" of the mining industry. Elvis and Frank described their time in the 1970s as full of contracts with mines, with workers leaving for another if they paid fifty cents more.

It was going good. Miner could get a job. Fuck, walk in the Capital Hotel, you had a job an hour later. The Capital Hotel used to be called the home of the miners then. Back in the late seventies and early eighties. I got more jobs outta there than I ever got outta [employment agency]. I never got one outta [employment agency] [laughing]. Fuck, all I had to do was walk in there and fuck, I had a job. (Interview, Elvis)

Two in the camp, two at the Cap. (Interview, Frank)

Adam, Barry, and Elvis, all older workers, have noted that these days have passed and work is now harder to find. According to Adam, workers are less likely to abandon their jobs for this reason. It also makes them more likely to tolerate poor conditions in the workplace. Additionally, the work available is precarious; for example, Adam has been employed for only a few months at a time, for multiple contractors, in the last year. For Barry, a professional, contract employment is also a reality, and he and his colleagues have found themselves looking to increasingly remote areas for work once their contracts end.

Interviewer: Is turnover really frequent there? Can you go back to a site and-

Respondent: Uh, not as much as the old days if you, if you're unhappy you'd go to a new job. You can't do that now. There's not that many jobs out there. So you gotta suck it up, put up with whatever bullshit's goin' on. (Interview, Adam) 
... it seems to me it's getting tougher out there, despite what everybody keeps saying about we need more and more people. It just doesn't look that way to me. But, so I think it's getting tougher out there, people are more willing to stay a lot of the time. I know in fact a couple, I've been working for a company this last winter that's, well basically my contract is finished with them next week. And uh, it won't be renewed. Well we had several people last summer, um, that, that we can't hire back, and they know that, and they're starting to look at some very ... um ... remote camps, things that they wouldn't consider normally ... people are uh, moving to wherever the jobs are now. They're more, they have a higher tolerance for rougher situations, and I think, lower pay. (Interview, Barry)

Non-local tradesmen Charlie and Leo noted that they had the opportunity to move elsewhere and find work. Charlie noted that while there were few jobs available to him in the mining industry in his trade, recruiters regularly contacted him for work through job-search sites in other industries. He was reluctant to switch simply because he enjoyed a high wage compared to where he worked in his home region, and the deciding factor for him to leave his position and migrate to other regions had to do with rotation schedules, distance to home, and how it would affect his family life. Similarly, Leo, a more experienced tradesman than Charlie, described multiple opportunities for work in mining outside of Canada, and that he was prepared to move to take advantage of these opportunities once his current contract had finished. In sum, the two non-local tradespeople noted they had options to pursue work in other industries, while the local labourers were limited in their choices.

I'm getting all kinds of job offers. Most of them have requiredasked me-to relocate and work in a town somewhere, like Timmins, Ontario or somewhere like that. My family and I are not willing or prepared to relocate. We're very happy where we are. We're very happy with my schedules. I mean four and two is always long, but for right now that's all I have, that's all there is right now. There's very few openings for mining electricians right now. This is what I like to do, and so I'm staying put until ... maybe something else comes along. Let's say a three week in, three week out rotation, somewhere else. (Interview, Charlie) 
Home Life

Discussion of private life at home was rarer among respondents, who preferred to keep the conversation focused on their experiences in the workplace. As such, the fourth theme is brief compared to the previous three. This is not necessarily because the home lives of respondents are unimportant; respondents may not have found their experiences in this area relevant to the study, or simply been uncomfortable talking about their personal lives. Still, respondents discussed how communication technology affected their home lives, as well as how long-distance commuting affected their leisure activities and family life.

Over half of the respondents brought up communications with home while they were at work. Communications technology has changed over the last few decades in mining, as noted by Barry. When he began in the mining industry in the 1970s, remote camps only had access to radios, and channels were generally kept clear for emergencies, grocery orders, or business reasons. Since then, remote camps have gained access to more sophisticated technology, including satellite phones and, in recent years, acces to Internet. This has important implications for workers and their families; now they are able to contact one another on a daily basis.

So yes, I like, I used to like to go having good food at like the big restaurants, and uh drinking cocktails, and just spending money, having fun with people in the bar and getting drunk. I was doing that just for one or two nights, not for the full week but ... it was a party. (Interview, Grace)

Many local respondents discussed celebrations when they returned from their rotations. For respondents Barry, Charlie, and Leo, who had families, there were no large celebrations when they returned home. For the respondents without families, their return to town meant a period of partying and leisure activities. Workers who returned to Whitehorse were eager to spend their wages on consumer goods and services. For Adam and Grace this meant good food at restaurants, a welcome change from what they considered to be poor food that was served at mine camps. Adam, Elvis, Grace, Jeremy, and Kirk all talked about the first couple of nights back in town being a party.

Uh when I'm away? Well, when I'm away just my daughter, she's 17 now, and my wife, so she has her things that she does: curling, goes to the gym, whatever our daughter needs. So it's like, there's a routine when I'm at home and there's a routine when I'm away, eh? (Interview, Leo) 
Yeah, then I think she liked it, ya know. Cause then she could run her own show at home when I wasn't there, ya know? No arguments about what the five-year old wasn't supposed to be doin, (Interview, Barry)

Respondents were asked about their family lives. Leo noted that both his wife and children had gotten used to it long ago; they had adapted well to rotations. He said that this took about a year. Barry agreed with this; he had been working as a professional for decades as well, and said that after about a year his wife had gotten used to his absence. Additionally, both of these respondents brought up that their time away from home was beneficial for their spouses. It gave them space to run the households as they wanted and raise children as they wanted; it gave their spouses independence while their husbands were away. Leo brought up that his wife had a wide social circle while he was away. Charlie reported different experiences for his wife:

I believe she works about [laughs] ten times harder than I do ... during a day, during her daily life, y'know. Cause she's not only getting the kids up and ready to go, and getting my son ready to go for school, but she's getting the daycare ready for, for 8 hours for that day, and then she's also got her studying and night course to do too. So ... she works very very hard. (Interview, Charlie)

While he was away his wife had to take on his responsibilities in addition to her own. She had to care for two children, take care of household chores and bills, while also running her side business, and studying for a correspondence course. Charlie brought up that he tried to do his part when he was home from his rotation, but she was on her own for three weeks at a time. For some there was a general feeling that they were missing out on the lives of their families and friends. Jeremy and Kirk talked about missing out on big events, like birthdays and other celebrations. Despite these observations, respondents did not feel their family lives were negatively affected by their work.

\section{Discussion}

This article outlines an initial exploratory study to determine future directions of research dealing with the mining industry and long-distance commuting in the Yukon. The findings of these interviews highlight several issues that could be the basis of more in-depth research. Some of the most interesting concern women and Aboriginal peoples. Our findings coincide with findings 
from similar studies. One of the most interesting similarities in terms of the workplace is between the experiences of Aboriginal people and women in the Yukon's mining industry, and the experiences of women described in the many chapters of Lewis et al. (1988a) dealing with the offshore oilfields. Beginning with women, Wybrow (1988) was writing at a time when women were less welcome in offshore oil work and reported negative attitudes toward them from managers and fellow workers. More recently, Costa et al. (2006) looked at the experiences of women at Canadian FIFO mining operations and found a number of issues with women starting families, as well as a high concentration of women in low-paying positions in mining. While this study was not able to be this specific about the situation of women in the mining industry, the respondents did highlight the masculine culture of mining in the Yukon and noted women were not found in underground mining, and often worked in service sector positions. As such, the situation of women in the Yukon's mining sectors appears to be worthy of more indepth research.

One of the greatest differences between the Yukon's mining industry and other industries is the existence of First Nation land claims, and the existence of Impact Benefit Agreements (IBAs) between companies and local populations. Ritter (2001) and Storey (2001) have brought up the use of these IBAs by Aboriginal groups in securing more employment and other benefits for their communities; in exchange, mining companies are able to develop on traditional lands. There is also an interesting connection between perceptions of affirmative action policies (Heen, 1988), the working environment for Aboriginal people in Canada (Gibson and Klinck, 2005), and the perceptions of IBAs among workers interviewed in the Yukon. In Heen (1988), some workers described affirmative action policies as a major problem in the offshore oil industry because they believed females were hired to fill a quota, rather than because of their qualifications. Multiple respondents in the Yukon described similar issues with Impact Benefit Agreements. They described high hiring rates for Aboriginal people, but also that Aboriginal people were hired regardless of qualifications. One Aboriginal respondent felt that this created a toxic work environment for him and other Aboriginal people, that he was scrutinized more heavily, and passed over for promotion because of this. The end result was that many Aboriginal people quit their jobs to avoid these environments. This corroborates the findings of Gibson and Klinck (2005), who described the negative attitudes from other workers that Aboriginal people often face in mining. To address these issues, some companies and Aboriginal communities, through Impact Benefit Agreements, have required cultural sensitivity training for all workers. While limited, the 
findings from our study clearly indicate that more research needs to be done to properly understand the place of Aboriginal workers in mining in the Yukon.

Issues surrounding safety were also described by workers in the Yukon, and comparisons with the literature are made here. Safety concerns have been brought up by workers in other studies involving commuting-based resource projects (Anger et al., 1988; Collinson, 1998, Parkes, Carnell, \& Farmer, 2005). Often, safety issues are associated with cost-cutting measures (Hart, 2002). These cost-cutting measures and their impact on workers are important to highlight because of how devastating accidents can be in mining work. To cite a Canadian example in mining, in 1992 the Westray coal mine in Nova Scotia also exploded, killing twenty-six people (Comish, 1993). While a major workplace accident like Westray has not happened recently in the Yukon, there have been safety violations within the last year in the territory (Kerr, 2013), and some workers' responses shared similarities with the issues at Westray. That said, the majority of respondents felt they worked in safe environments, and that the safety practices at their sites were well done. According to respondents, workers who felt unsafe at certain FIFO operations in the Yukon looked for work elsewhere and, as such, operations experienced high turnover rates. Perception of safe work environments seems like another important area of future study if the Yukon hopes to ensure a more efficient operation of its FIFO and DIDO mines.

There were some similarities between the experiences of workers in the Yukon and the available literature in terms of migration. Both local and nonlocal respondents discussed inter-provincial migration for the purpose of employment, and older local respondents experienced internal migration within the Yukon over their decades of working as miners. This included the two Aboriginal respondents who migrated between Whitehorse and smaller communities in the Yukon. Southcott (2010) discussed recent migration trends in the Yukon. Local workers, specifically Aboriginal workers, tend to migrate around the territory but not outside of it. People across Canada have traditionally migrated to the Yukon in order to exploit its natural resources, and this trend continues even today. These people spend a short time in the territory for employment before returning to their home regions. Finnie (2004) explored this population of interprovincial migrants in Canada, and found that they are more likely to come from home regions with low populations and high rates of unemployment or otherwise poor economic conditions. The two non-local respondents in this study fit the descriptions of migrants well; they migrated for work opportunities in the Yukon's 
mining industry, came from rural areas with poor economic conditions, and planned on leaving the territory again once their current contracts ended.

One of the most important differences between the experiences of Yukon respondents and findings in the available literature was the way workers experienced the transition between home and work. This could be due to differences in the structure of the Yukon's mining industry, which differentiates it somewhat from other FIFO dependent regions. Workers in other jurisdictions tended to feel a lonely isolation from home when they are at work (Lewis et al., 1988a). While the same is true for the two respondents who commuted from outside the territory, many of the local respondents drove to their workplaces, and following their shifts were not trapped at their work camps. These respondents viewed commuting this way as liberating, and had few issues with the commuting lifestyle. As for the two respondents who commuted from outside the Yukon, their situation bears resemblance to the long-distance workers discussed in Elmsteiner-Saxinger's (2010) study. Elmsteiner-Saxinger brought up a unique social space that connected the home and work lives of long-distance workers in Russia. Many of the respondents, both local and non-local, reported relocating numerous times for work over the course of their careers. This trend has been documented by Elmsteiner-Saxinger (2010), who described that moving from job to job was celebrated as a way of life among long-distance commute workers. Indeed, many local respondents shared this sentiment, and described themselves and fellow miners as mobile.

Though they considered themselves local at the time of their interviews, some respondents gave accounts of times when employment prospects were poor in the Yukon, and they were forced to move to other regions for work. Similarly, in Allan's (2011) account of the relocation culture in Australian mining, some long-distance commute workers described the many opportunities that came with relocating their families; some felt it allowed their family to move from small towns to urban centres with better infrastructure and access to services. This was certainly the case for one non-local respondent, Charlie; he left his last job and moved his wife and newborn child to an urban centre so that they could live well, and he commuted across the country for his new job. The two non-local workers, who travelled longer distances than the other respondents, appeared to be impacted the most from their rotations at work. It is here where a connection can be made between Clark and Taylor's (1988) concepts of novices and veterans in offshore resource work, where veterans are supposed to have adapted very well to the changes. One participant had been married and commuting long distances for over twenty years. His description of home 
life was that it was not stressful and the family had adapted well to the problems of the lifestyle, while the other participant who travelled from eastern Canada was still adapting - he was considering leaving the industry altogether, and had just started a family. He was somewhere between these ideal novice and veteran stages.

The changes in communications technology over the last couple of decades appear to have had an impact on the home lives of long-distance mining workers. Older studies (Lewis et al., 1988a; Collinson, 1998) and recent work on FIFO mining (Torkington et al., 2011) have cited lack of communication as a major issue for workers and their families. Some oil platforms had poor access to phones, or intermittent service, making communication between home and work difficult. In 2013, respondents described the opposite situation in FIFO operations in the Yukon. Respondents had access to phones and even Internet access, and the nonlocal respondents talked about frequent communication with their wives and children. Local and single FIFO workers in the Yukon had few concerns with their home lives, and this lifestyle suited them well. They were able to keep in contact with friends and family back home, thanks to newer communications technology. Once at home, most of their time was spent celebrating their time off work. Non-local workers with families made greater use of phone and the Internet to keep in touch with their spouses and children back home frequently. The level of experience non-local workers had living a FIFO lifestyle determined whether they felt negative impacts at home. Novice non-local FIFO workers and their families may experience more stress and fatigue in their home lives as they adjust to commuting to areas far from their home regions. By contrast, veteran non-local FIFO workers may have developed strategies to cope with the challenges of longdistance commuting. Therefore, a major benefit of employing local Yukon workers in FIFO operations would be the insignificant impacts on their home lives. More in-depth research into the unique patterns of work and home separation in the Yukon's commuting workforce could lead to a better understanding of how to make this separation more acceptable to workers.

\section{Conclusions}

As the mining industry changes, and as it attempts to re-establish itself as the most important economic activity in the Yukon, it is important to try and develop a deeper understanding of those who work in the mines, and their concerns. The economic future of the territory is at least partially dependent on both ensuring that it can attract qualified outside workers when needed and on ensuring that its own regional workforce is ready to take advantage 
of new opportunities presented by the trend towards mobile miners. Our exploratory study gives some ideas of future research areas that could give us a better notion of how to do this. In particular, the situation of women in new mining operations, Aboriginal employment experiences, perceptions of safety, and the separation of home and work are all important questions for new research.

In some ways, many of the issues in mining have not changed, as there were many similarities across studies conducted between the late 1980s and the time of writing. Women continue to make up a small proportion of the mining workforce, and although they have entered open-pit mining in greater numbers, their highest concentration is still in support roles. There is also still resistance to hiring policies regarding diversity, although the resistance is directed at the hiring of Aboriginal people as set out in new Impact Benefit Agreements in the Yukon, rather than employment equity legislation. Aboriginal people continue to experience negative workplace environments in mining. More recent issues emerged from respondents' experiences as well, and these are more closely connected to restructuring in the Canadian mining industry. Safety and training issues continue to be concerns among some respondents. While many respondents have cited the existence of safety procedures and trained personnel, others have claimed there is inadequate training or equipment missing in some locations. The respondents who described these issues felt they were due to cost-cutting measures on the part of their companies. The precarious nature of mining work, especially for those at the bottom of the hierarchy, was also a common experience. Companies have moved from hiring their own employees to sub-contracting workers for their front-line operations. These positions are often occupied by local workers, including workers from First Nations communities. For skilled trades, where there are often shortages, companies also rely on contractors. Out of necessity these contractors currently hire non-local tradespeople, who must then bear the negative aspects of longdistance commuting discussed above.

The issues described above are connected to the lean production models that have become the norm for mining companies in Canada. In the last three decades, companies have used a number of cost-cutting methods to run their operations more efficiently. For mining, one of the primary methods has been long-distance commuting operations, which is cheaper than the alternative of constructing towns at the sites of mines. Instead, camps are set up in remote regions near mines, and small numbers of skilled and flexible workers commute from their home communities for extended rotations. They are small in number, as mining has become more capital- 
intensive therefore reducing the number of jobs; they are more skilled, as mining equipment is more technologically advanced; they are more flexible, as companies hire contractors for their front-line operations, making work unstable for workers and less expensive for companies.

For regions such as the Yukon that are trying to ensure mining contributes to the long-term sustainability of the region, long-distance commuting is a paradox. It has the potential to avoid some of the negative impacts of the boom and bust cycle associated with mining, but at the same time results in fewer jobs for people living in the region. The paradox can be partially resolved by a balance between use of outside workers when necessary and use of local workers when possible. For this balance to be achieved, a better understanding of the experiences of these workers is necessary. This study provides us with an initial understanding of some of these experiences, but more research is necessary in order to assist regions such as the Yukon to better utilize long-distance commuting so as to ensure greater benefits from mining for northern communities.

\section{Authors}

Christopher Jones recently completed an MA in sociology at Lakehead University.

Chris Southcott is professor of sociology at Lakehead University in Thunder Bay, Ontario and principal investigator of the SSHRC funded

Resources and Sustainable Development in the Arctic (ReSDA) network.

\section{Notes}

1. For the purposes of this article, the term local will refer to those living in the Yukon Territory.

2. For a discussion of regional-based commuting in the Northwest Territories see Davison \& Hawe, 2012.

3. The Lakehead University Research Ethics Board granted approval for this study in January 2013. A Yukon Government Research Licence was issued in February 2013.

4. A more detailed description of the methodology used can be found in Jones, C. "Mobile Miners: Work, home, and hazards in Yukon's mining industry," Master's Thesis, Lakehead University, December 2013. Available at www. resda.ca. 


\section{References}

Allan, J. (2011). Mining's relocation culture: The experiences of family members in the context of frequent relocation. International Journal of Sociology and Social Policy, 31(5/6), 272-286.

Anger, D., Cake, G., and Fuchs, R. (1988). Women on the rigs in the Newfoundland offshore oil industry. In J. Lewis, M. Porter, and M. Shrimpton (eds.), Women, work, and family in the British, Canadian, and Norwegian offshore oilfields (pp. 82101). London: The MacMillan Press Ltd.

Carrington, K. and Pereira, M. (2011). Assessing the social impacts of the resources boom on rural communities. Rural Society, 21(1), 2-20.

Clark, D., and Taylor, R. (1988). Partings and reunions: Partings and reunions in the British North Sea. In J. Lewis, M. Porter, and M. Shrimpton (Eds.), Women, work, and family in the British, Canadian, and Norwegian offshore oilfields (pp. 112-139). London: The MacMillan Press Ltd.

Coates, K., and Morrison, W. (2005). Land of the midnight sun. Montreal \& Kingston: McGill-Queens University Press.

Collinson, D. L. (1998). Shift-ing lives: Work-home pressures in the North Sea oil industry. The Canadian Review of Sociology and Anthropology, 35 (3), 301-324.

Comish, S. (1993). The Westray tragedy: A miner's story. Halifax: Fernwood Publishing.

Costa, S. D., Silva, S. C. and Hui. V. (2006). What are the opportunities and challenges for women in fly-in fly-out (FIFO) mining in Canada? Norman B. Keevil Institute of Mining Engineering, University of British Columbia, Vancouver.

Davison, C. M., \& Hawe, P. (2012). All that glitters: Diamond mining and Taicho youth in Behchoko, Northwest Territories. Arctic, 65(2), 214-228.

Elmsteiner-Saxinger, G. (2010). Multiple locality and socially constructed spaces among interregional Vakhtovikki. In F. Stammler and G. Elmsteiner-Saxinger (Eds.), Biography, shift-labour and socialisation in a northern industrial city Particularities of labour and socialisation, (pp.132-138). Arctic Centre, University of Lapland, Finland.

Finnie, R. (2004). Who moves? A logit model analysis of inter-provincial migration in Canada. Applied Economics, 36(16), 1759-1779.

Gibson, G., and Klinck, J. (2005). Canada's resilient north: The impact of mining on aboriginal communities. Pimatisiwin: A Journal of Aboriginal and Indigenous Community Health, 3(1), 115-139.

Hart, S. (2002). Norwegian workforce involvement in safety offshore: Regulatory framework and participants' perspectives. Employee Relations, 24(5), 486-499.

Hayter, R. (2003). The war in the woods: Globalization, post-Fordist restructuring and the contested remapping of British Columbia's forest economy. Annals of the Association of American Geographers, 96, 706-29.

Horne, M. C. (2010). Yukon's self-governing First Nations. Canadian Parliamentary Review, 2-8. 
Jenson, Jane. (1989). 'Different' but not 'exceptional': Canada's permeable Fordism. Canadian Review of Sociology and Anthropology, 26(1), 69-94.

Jones, C. "Mobile miners: Work, home, and hazards in Yukon's mining industry," Master's Thesis, Lakehead University, December 2013. www.resda.ca.

Kerr, J. (2013). Tagish Lake Gold Corp. to pay for safety infractions. Yukon News, March 6, 2013. Retrieved June 20, 2013 from http://yukon-news.com/news/ tagish-lake-gold-corp.-to-pay-for-safety-infractions.

Lewis, J., Porter, M., and Shrimpton, M. (1988a). Introduction. In J. Lewis, M. Porter, and M. Shrimpton (Eds.), Women, work, and family in the British, Canadian, and Norwegian offshore oilfields (pp. 1-20). London: The MacMillan Press Ltd.

Lewis, J., Porter, M., and Shrimpton, M. (1988b). Family members' experience of offshore oil work in Newfoundland. In J. Lewis, M. Porter, and M. Shrimpton (Eds.), Women, work, and family in the British, Canadian, and Norwegian offshore oilfields (pp. 163-189). London: The MacMillan Press Ltd.

Mining Human Resources Council. (2011a). Canadian mining industry employment and hiring forecasts 2011. Mining Human Resources Council.

Mining Human Resources Council. (2011b). Making the grade: Human resources challenges and opportunities for knowledge workers in Canadian mining. Mining Human Resources Council.

Newhook, J. T., Neis, B., Jackson, L., Roseman, S. R., Romanow, P., and Vincent, C. (2011). Employment-related mobility and the health of workers, families, and communities: The Canadian context. Labour, 67(1), 121-156.

O'Faircheallaigh, C. (2010). Aboriginal-mining company contractual agreements in Australia and Canada: Implications for political autonomy and community development. Canadian Journal of Development Studies, 30(2), 69-86.

Parkes, K. R., Carnell, S. C., and Farmer, E. L. (2005). Living two lives. Community, Work \& Family, 8(4), 413-437.

Pasloski, D. (2012). Budget address 2012-2013. Whitehorse, YT: Yukon Legislative Assembly.

Ritter, A. R. M. (2001). Canada: From fly-in, fly-out to mining metropolis. In F. Remy and G. McMahon (Eds.), Large mines and the community: Socioeconomic and environmental effects in Latin America, Canada, and Spain (pp. 223-261). Washington: World Bank.

Roos, D., Womack, J., and Jones, D. (1991). The machine that changed the world: The story of lean production. Toronto: Harper Perrenial.

Russell, B. (1999). More with less: Work reorganization in the Canadian mining industry. Toronto: University of Toronto Press.

Southcott, C. (2010). Migration in the Canadian north: An introduction. In L. Huskey and C. Southcott (Eds.), Migration in the Circumpolar North: Issues and Contexts (pp. 35-55). Edmonton: CCI Press.

Storey, K. (2001). Fly-in/fly-out and fly-over: Mining and regional development in Western Australia. Australian Geographer, 32(2), 133-148. 
Storey, K. (2010a). Fly-in/Fly-out: Implications for community sustainability. Sustainability, 2(5), 1161-1181.

Storey, K. (2010b). The evolution of commute work in Canada and Australia. In F. Stammler and G. Elmsteiner-Saxinger (Eds.), Biography, shift-labour and socialisation in a northern industrial city - Particularities of labour and socialisation (pp. 23-31). Arctic Centre, University of Lapland, Finland.

Taylor, F. (1947)[1911]. Scientific management. New York: Harper \& Brothers Publishers.

Torkington, A. M., Larkins, S., and Gupta, T. S. (2011). The psychosocial impacts of fly-in fly-out and drive-in drive-out mining on mining employees: A qualitative study. The Australian Journal of Rural Health, 19(3), 135-141.

Wybrow, P. (1988). Equal opportunities in the North Sea. In J. Lewis, M. Porter, and M. Shrimpton (Eds.), Women, work, and family in the British, Canadian, and Norwegian offshore oilfields (pp. 35-61). London: The MacMillan Press Ltd.

Yukon Bureau of Statistics. (2010a.) Yukon Business Survey 2010. Whitehorse: Yukon Bureau of Statistics. Retrieved August 14, 2012 from http://www.eco.gov.yk.ca/ stats/pdf/2010_Business_Survey_Report.pdf. 